\title{
A Review on Magneto-Caloric Materials for Room Temperature Refrigeration
}

\author{
S. M. Gombi ${ }^{1}$ and D. Sahu2* \\ 1Department of Mechanical Engineering, Amrita School of Engineering, Bengaluru, Amrita Vishwa Vidyapeetham, India. \\ ${ }^{2}$ School of Mechanical Engineering, Kalinga Institute of Industrial Technology, Bhubaneswar 751024, Phone: +91 8970863768
}

ABSTRACT - Magnetic refrigeration is an environment-friendly technology when compared to the conventional gas compression system known as vapor compression refrigeration system. Room temperature magnetic refrigeration is a technology which relies on a solid material known as the magneto-caloric material (MCM) which exhibits magneto-caloric effect (MCE) near room temperature. The magneto-caloric effect is the change in temperature of a magnetic material when that material is either magnetized/demagnetized adiabatically. This review is focused on the selection of a suitable MCM which exhibits near-room-temperature MCE. It also explains a methodology to estimate the amount of material required, based on the cooling load or refrigeration capacity (RC) calculation.
ARTICLE HISTORY

Revised: $14^{\text {th }}$ Dec 2019

Accepted: $5^{\text {th }}$ Jan 2020

\section{KEYWORDS}

Magnetic refrigeration, Magneto-caloric material, Metallic glasses.

\section{NOMENCLATURE}

\begin{tabular}{|c|c|c|c|}
\hline GWP & global warming potential & $\mathrm{C}_{\mathrm{H}}$ & specific heat $(\mathrm{J} / \mathrm{kgK})$ \\
\hline VCR & vapor compression refrigeration & $\mathrm{ECE}$ & elastocaloric effect \\
\hline AMR & active magnetic regenerative & COP & coefficient of performance \\
\hline HHX & hot heat exchanger & $\mathrm{f}$ & frequency $(\mathrm{Hz})$ \\
\hline $\mathrm{CHX}$ & cold heat exchanger & $Q_{\text {avg }}$ & heat generated $(\mathrm{J})$ \\
\hline $\mathrm{RC}$ & refrigeration capacity $(\mathrm{J} / \mathrm{kg})$ & $\Delta \mathrm{H}$ & magnetic field change (Tesla) \\
\hline FOM & first order material & $\mathrm{T}_{\mathrm{c}}$ & Courie temperature $(\mathrm{K})$ \\
\hline SOM & second order material & $\varepsilon$ & effectiveness of heat exchanger \\
\hline$\Delta \mathrm{S}_{\mathrm{M}}$ & isothermal magnetic entropy change $(\mathrm{J} / \mathrm{kgK})$ & $\mathrm{Q}_{\mathrm{c}}$ & cooling load $(\mathrm{J} / \mathrm{s})$ \\
\hline $\mathrm{S}$ & total entropy $(\mathrm{J} / \mathrm{kgK})$ & $\mathrm{m}$ & mass of magnetocaloric material $(\mathrm{kg})$ \\
\hline $\mathrm{S}_{\mathrm{T}}$ & thermal entropy $(\mathrm{J} / \mathrm{kgK})$ & $\mathrm{W}$ & work absorbed in refrigeration system $(\mathrm{J} / \mathrm{s})$ \\
\hline$\Delta \mathrm{T}_{\mathrm{ad}}$ & adiabatic temperature change $(\mathrm{K})$ & & \\
\hline
\end{tabular}

\section{INTRODUCTION}

Approximately $15 \%$ of total energy utilization is directly or indirectly related to refrigeration [1]. Reduction in consumption of electricity will greatly reduce the amount of harmful gases released in the atmosphere during its generation. Man's accomplishments have increased the level of greenhouse gases in the environment, leading to subtle warming up of the planet. The Global Warming Potential (GWP) is defined as the mass of $\mathrm{CO}_{2}$ that would cause the same net effect as a single unit $(\mathrm{kg})$ of the component would, on global warming. Conventional Vapor Compression Refrigeration (VCR) cycle uses hydro-chlorofluorocarbon or hydrocarbon refrigerant and vapor absorption cycle uses ammonia [2]. The refrigerants used nowadays do not cause any ozone depletion, however, the GWP is considerably high [3]. Magnetic refrigeration is a developing technology, it has sparked great interest due to its environment-friendly working principle and its ability to consume $20 \%$ less electricity than the conventional VCR system [4]. Generally, MCM has zero direct GWP and ODP (Ozone Depletion Potential).

When a Magneto-Caloric Material (MCM) is brought closer to a permanent magnet it gets magnetised as shown in Figure1 (the elliptically shaped magnet with the north and south poles indicated by $\mathrm{N}$ and $\mathrm{S}$ respectively). Similarly, when the MCM is moved away from the external magnetic field (demagnetised) its temperature decreases. A magnetic refrigerator is designed to exploit this temperature drop to produce a cooling effect. Under adiabatic demagnetisation the magnetic entropy increases, causing a decrease in lattice vibrations and resulting in a temperature drop. Similarly, if magnetisation is done at a constant temperature, it reduces the material's magnetic entropy and this is represented as the isothermal entropy change $\left(\Delta \mathrm{S}_{\mathrm{M}}\right)$.

When the magnetisation is done adiabatically there will be a rise in the temperature $\left(\Delta \mathrm{T}_{\mathrm{ad}}\right)$ of the MCM. This is because the magnetic dipoles in the MCM, in the presence of the magnet, align themselves to the external magnetic field created by the magnet [5]; its magnetic entropy, $\mathrm{S}_{\mathrm{M}}$ reduces. It is an adiabatic process and the total entropy, $\mathrm{S}$ must remain constant, its thermal entropy, $\mathrm{S}_{\mathrm{T}}$ (directly proportional to temperature) increases. The entropy of a system comprises of lattice (thermal) entropy, electronic entropy and magnetic entropy. Change in entropy is given by equation (1) where $\mathrm{S}$ is entropy, $\mathrm{T}$ is temperature and $\mathrm{H}$ is magnetic field. 


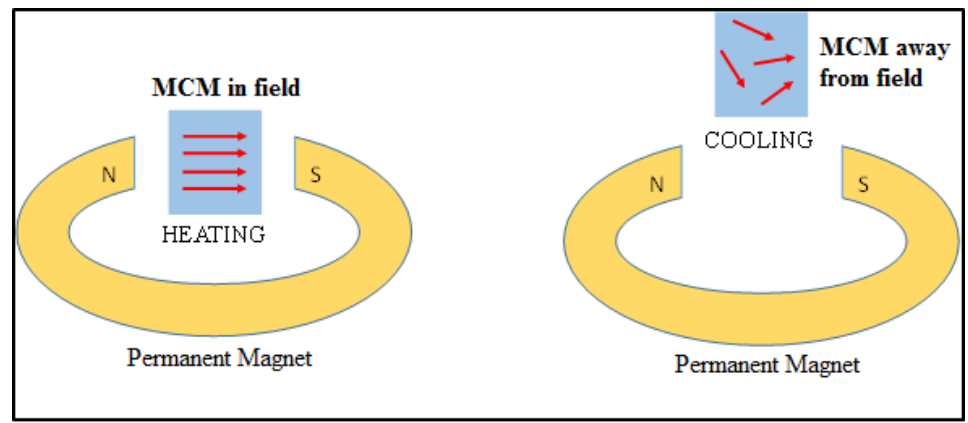

Figure 1. The MCE resulting in temperature change; arrows represent magnetic moment [5].

$$
\begin{gathered}
\mathrm{dS}=\left(\frac{\partial \mathrm{S}}{\partial \mathrm{T}}\right)_{H} \mathrm{dT}+\left(\frac{\partial \mathrm{S}}{\partial H}\right)_{\mathrm{T}} \mathrm{d} H \\
\Delta \mathrm{S}_{\mathrm{M}} \approx \frac{1}{\Delta \mathrm{T}}\left[\int_{0}^{H} \mathrm{M}\left(\mathrm{T}+\Delta \mathrm{T}, H^{\prime}\right) \mathrm{d} H^{\prime}-\int_{0}^{H} \mathrm{M}\left(\mathrm{T}, H^{\prime}\right) \mathrm{d} H^{\prime}\right]
\end{gathered}
$$

McMichael et al., presented a formula for the evaluation of $\triangle \mathrm{S}_{\mathrm{M}}$ of MCM, using $\mathrm{M}-\mathrm{H}$ curves (magnetisation versus the external applied field), which is shown in equation (2) [6]. Specific heat-temperature $\left(\mathrm{C}_{\mathrm{H}}-\mathrm{T}\right)$ curves of MCMs can be used to calculate $\Delta \mathrm{S}_{\mathrm{M}}$ and $\Delta \mathrm{T}_{\mathrm{ad}}$. Mathematically, magnetic entropy change is equal to the area between the two magnetic isotherms divided by corresponding temperature difference between them. Relative cooling power or refrigeration capacity is the product of $\Delta \mathrm{S}_{\mathrm{M}}$ and $\Delta \mathrm{T}_{\mathrm{ad}}[1]$.

Interestingly, if the magnetisation is done in isolation, the total entropy would remain unchanged and the reduction in magnetic entropy is counteracted by a rise in the thermal entropy; the material is heated up, and the temperature rise is also known as the adiabatic temperature change $\left(\Delta \mathrm{T}_{\mathrm{ad}}\right)$. This phenomenon can be explored for heating application. If the temperature change is observed in material on application of external pressure at constant magnetic field then its called Elastocaloric effect (ECE) [7].

Many researchers like Gutfleisch et al. established that studying adiabatic temperature change and isothermal entropy change are most significant [8]. Aprea et al., reported a 2D numerical simulation on various magnetocaloric, electrocaloric, mechanocaloric and barocaloric material used in a hypothetical refrigeration system similar to magnetic refrigeration system and claimed the superiority of electrocaloric material [9]. The best COP was obtained with $\mathrm{Pb}_{0.97} \mathrm{La}_{0.02}\left(\mathrm{Zr}_{0.75} \mathrm{Sn}_{0.18} \mathrm{Ti}_{0.07}\right) \mathrm{O}_{3}$ that ensures cold temperature drop $\sim 40 \mathrm{~K}$, with a cooling load in the range of $1.01-1.8$ $\mathrm{kW}$ but require an electric field $\sim 598 \mathrm{kV} \mathrm{cm}^{-1}$. This requirement of grid power might not be feasible to develop a sustainable refrigeration system.

\section{Magnetic Refrigeration Cycle}

Barclay (1982) introduced the AMR regenerator concept i.e., the use of the magnetic material as a refrigerant as well as a regenerator [5] for an ultra-low temperature application ( $\sim 20$ to $75 \mathrm{~K})$. The working cycle is known as the active magnetic regenerative (AMR) refrigeration cycle (magnetic Brayton cycle). It consists of a matrix of the solid refrigerant material (MCM), auxiliary fluid, hot heat exchanger (HHX), cold heat exchanger (CHX) and magnet(s). The auxiliary fluid passes through the tubes surrounded by MCM and extract or reject heat cyclically. AMR cycle consists of four steps which are as follows (Figure 2 represents the cycle).

i. Magnetisation: The MCM is magnetised by a permanent magnet and the temperature of the matrix increases. Therefore the level of magnetisation needed is important [10].

ii. Cold blow: The auxiliary fluid which is at the same temperature as the CHX is pumped past the matrix and extracts heat from the matrix, restoring the solid MCM to its initial temperature. This occurs under isomagnetic field conditions. The fluid then loses heat to the surrounding. Now the fluid and the HHX are at the same temperature.

iii. Demagnetisation: The MCM is demagnetised by moving away from the permanent magnet and its temperature falls below its original temperature.

iv. Hot blow: The auxiliary fluid is now pumped from HHX to $\mathrm{CHX}$ and on its way it loses its heat to the matrix. When it reaches the CHX it extracts heat from the environment to be cooled.

Thus a magnetic refrigerator prototype is built [11]. If the average heat generated is $\mathrm{Q}_{\text {avg, }}$ the coefficient of performance $=\mathrm{Q}_{\mathrm{avg}} / \mathrm{W}$, where $\mathrm{W}$ is the work required by the refrigeration system [12], accounting for parasitic losses too. If $Q_{\text {avg }}$ increases (mass $\times$ average specific heat $\times$ average change in temperature), then the COP also increases. Yu et al. provided a thorough material information to understand important aspects related to room temperature magnetic refrigeration [13]. They discussed about Magnetic Ericsson cycle and Magnetic Brayton cycle and proposed Brayton cycle to exhibit optimum performance. Currently, this technology is not commercial because of various challenges. The challenges include [14]: 
i. Developing magnetic materials exhibiting giant MCE near room temperature,

ii. Availability of raw material and a simple process of manufacturing,

iii. Sustainability of MCE at adverse condition and reversibility.

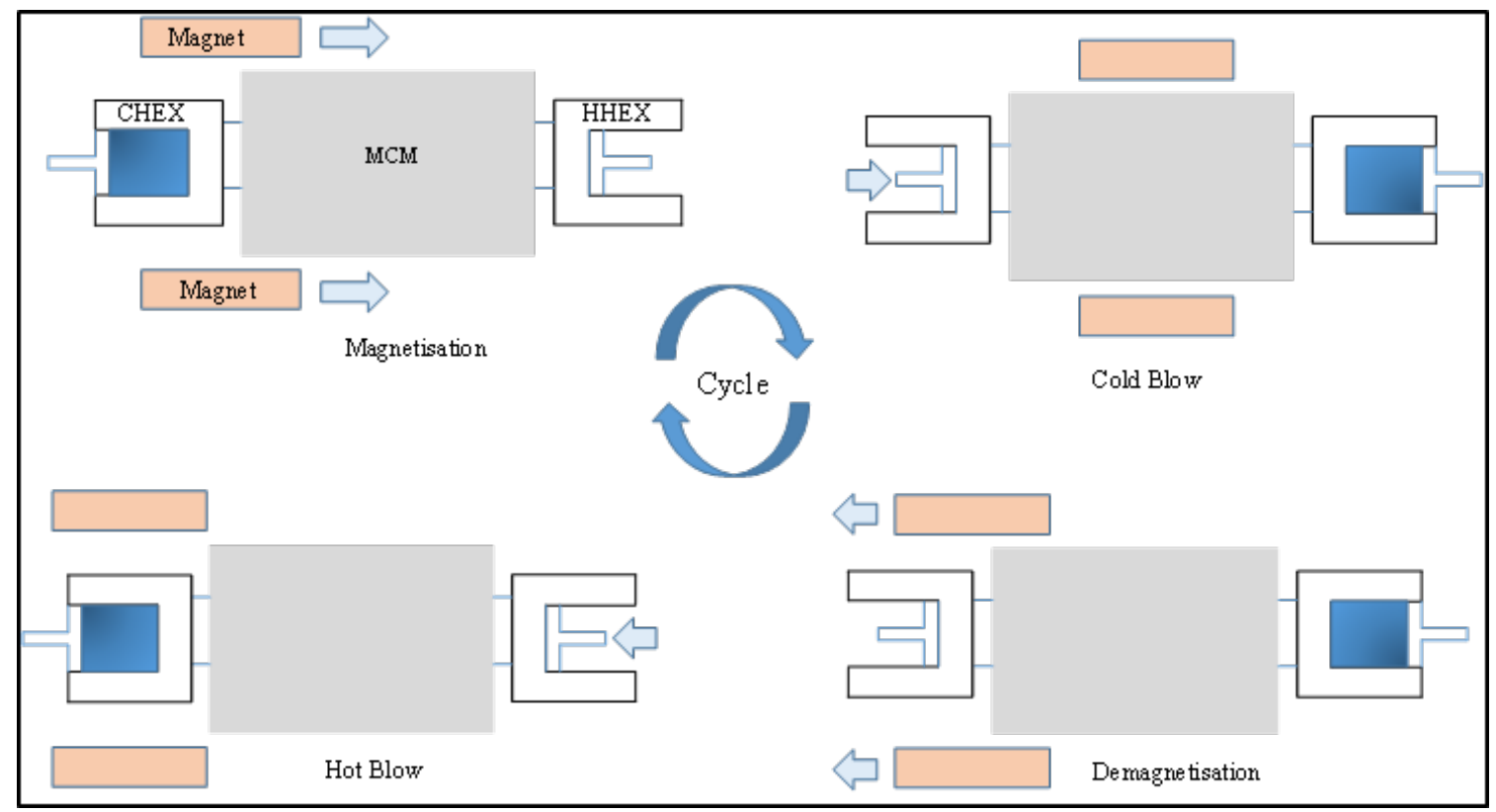

Figure 2. The AMR cycle [1].

There are reviews published focusing on AMR system [10]. One crucial aspect established by these reviews are the level of magnetisation required. Sarlah et al. numerically investigated the operation of a stationary and rotary type Active Magnetic Regenerators (AMR) [14]. To obtain a faster response in temperature and a high rate of heat transfer between the MCM bed and the heat-transfer fluid, the thermal conductivity and thermal diffusivity of the MCM must be as high as possible. However, the high thermal conductivity may also hinder the AMR refrigerator's performance because heat transfer taking place within the MCM bed itself, parallel to the fluid flow. Due to the frequent alteration of the external magnetic field eddy current may form in the MCM. This might result in heating up of the material which hinder the performance. This can be prevented by selecting a material with high electrical resistivity. Metallic glass type material is an option here hence this review focusses on the metallic glasses. It is necessary to study the factors that may control the MCE. Physicists and material scientists have attempted to study mainly [10] effect of Curie temperature, hysteresis loss, thermal conductivity, thermal diffusivity and crystallinity that affect MCE.

Kulkarni's review of room temperature magnetic refrigeration cites easy oxidation of magnetic material and high cost as the bottleneck [15]. Álvarez et al. showed that there is an improvement in the refrigeration capacity (RC) when a composite system of ribbon is used as compared to the pure alloy ribbon used in the AMR system [16]. Dung et al. studied the effects of the lattice site occupation and the composition of the compound on the MCE [17]. They varied Manganese (Mn) and Iron (Fe) percentage in the alloy of Mn-Fe-P and Mn-Fe-Si and observed a giant MCE with small thermal hysteresis [17]. In a critical view, Magen et al. observed that the influence of hydrostatic pressure on MCE is a distinct phenomenon in case of single crystalline structure though the anisotropic behaviour of lattice is preserved [18]. Gorria et al. showed that nano-sized MCMs show better MCE and they used ball milling to produce MCM that can be used in an AMR [19]. However, the nano material will be prone to oxidation faster [20]. To establish a commercially viable system it's better to focus on bulk material. There are reviews published on MCE of Nano material [20]. This review is focussing on bulk material and the material which are potentially cheap. The majority of literature published were focussed on various MCMs whereas the material optimisation for magnetic refrigerator is rarely reported. However to understand the basics first the magnetic transition is reviewed and then two type of material namely metal alloy and metallic glasses are reviewed here.

This review emphasises on thorough study of various magnetic material and then identifying the suitable MCMs which exhibit near-room-temperature MCE. There could be a good number of interesting materials, classifying them will be helpful for the future researchers to focus on a particular type of material, say, a particular type of metal alloy or metallic glass. Finally the MCM responding to low level of magnetisation (say, 2 Tesla) are identified from the literature. To check the feasibility of a real AMR system it's important to find how much such magnetic material will be needed, say, to develop a $0.1 \mathrm{~kW}$ refrigerator (most popular single door refrigerators are working at $\sim 0.1 \mathrm{~kW}$ ). Considering the identified materials a methodology to estimate the amount of material required, based on the refrigeration capacity (RC) is proposed which is simple and universal. 


\section{MAGNETO-CALORIC MATERIALS}

The important characteristic which an MCM must exhibit is its capability to attain peak MCE at/around the working temperatures (say, room temperature) [21]. The indicator of the peak MCE of an MCM is the Curie temperature itself. It is the temperature at which the phase transition between the ferromagnetic and paramagnetic phases occurs [22]. At temperatures that are reasonably distant from the Curie temperature the magnetocaloric effect is usually not considered significant. The exhibition of the MCE is preferred to be spread over a wide temperature range. This is crucial in an AMR refrigeration cycle as there is a temperature gradient that develops over the MCM bed during operation. The wide range of temperature in which the MCE occurs ensures that the entire material exhibit the MCE. Shen et al. aptly explained applicability of giant MCE materials to the magnetic refrigeration near room temperature and also explained how to determine MCE so that an AMR system can be designed [23]. Engelbrecht and Bahl studied the effect of temperature change and entropy change on the performance. They reported that the adiabatic temperature change in a magnetocaloric material can be more important than the isothermal entropy change [24].

\section{First and Second Order Transition}

The MCMs are divided into two groups depending on their phase transition from the ferromagnetic to paramagnetic state: i) first-order material (FOM) and ii) second-order material (SOM) [10]. The temperature ranges of the MCE of SOMs (e.g. Gd) is larger than those exhibited by the FOMs. At a certain temperature known as the Curie temperature, the ferromagnetic to paramagnetic state transition occurs. Spontaneous magnetisation vanishes beyond the Curie temperature and the material then transforms into a paramagnetic one. Furthermore, the MCE is maximum during this phase transition [25]. The way the transition occurs is what differentiates a first-order material from a second-order material (shown in Figure 3 and Figure 4 respectively). The arrows indicate the direction of increasing external magnetic field, $\mathrm{H}$ values. Typically, hysteresis occurs in FOMs (as in Figure 3(a)) and not in SOMs (as in Figure 3(b)).

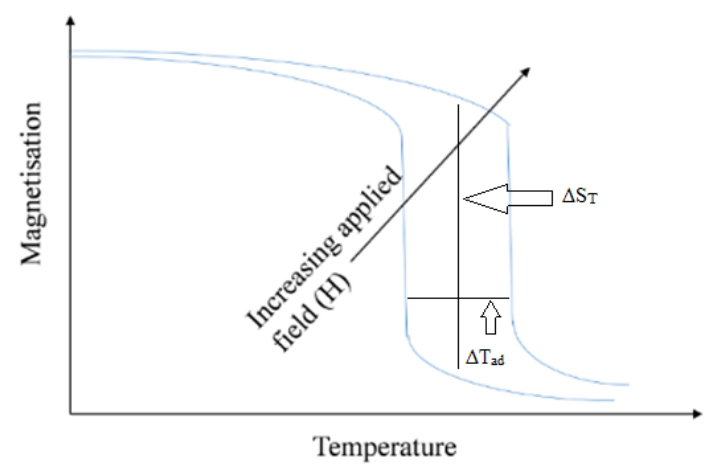

(a)

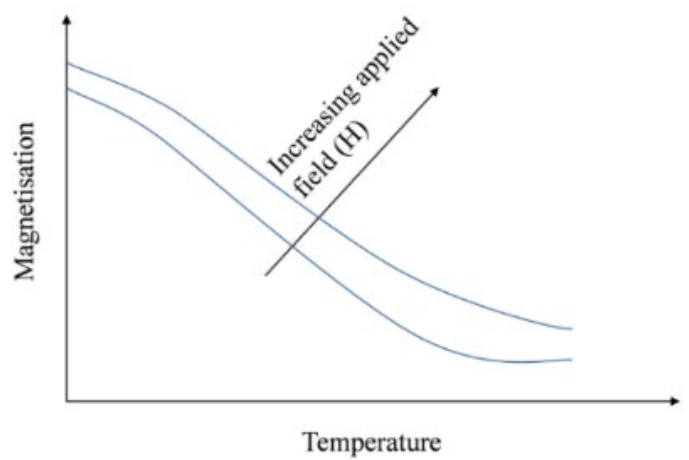

(b)

Figure 3. (a) First order magnetic transition and (b) second order magnetic transition [10].

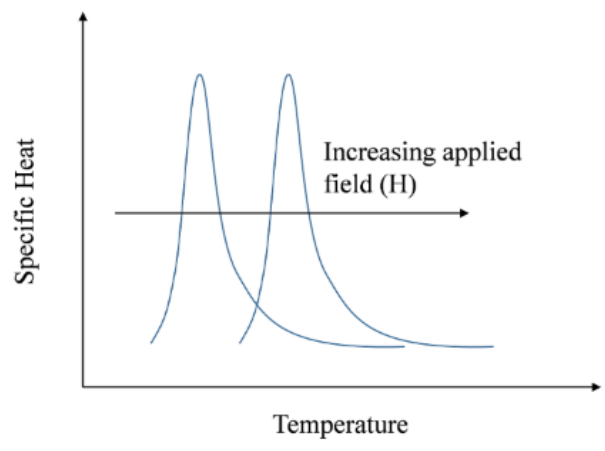

(a)

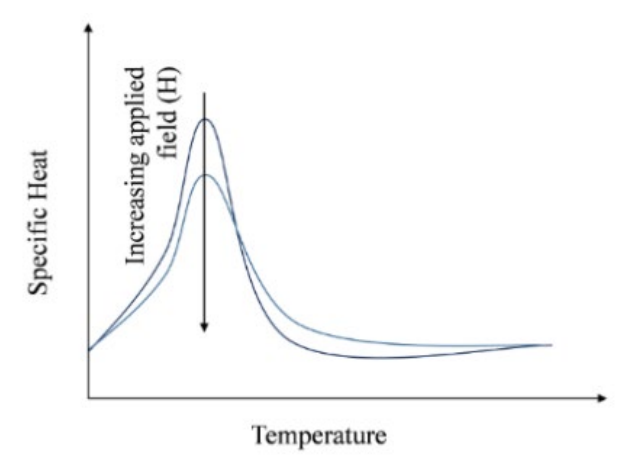

(b)

Figure 4. Specific heat of (a) $1^{\text {st }}$ order magnetic transition and (b) $2^{\text {nd }}$ order magnetic transition [1].

The specific heat variation with temperature for increasing magnetic fields is also different for FOM and SOM. Figure 4(a) and 4(b) which depict this difference, have specific heat in the horizontal axes and temperature in the vertical axes. The arrows indicate the direction of increasing $\mathrm{H}$ values. The basic differences in the behaviour of first and second order magnetic transition materials are summarised in Figure 5. 


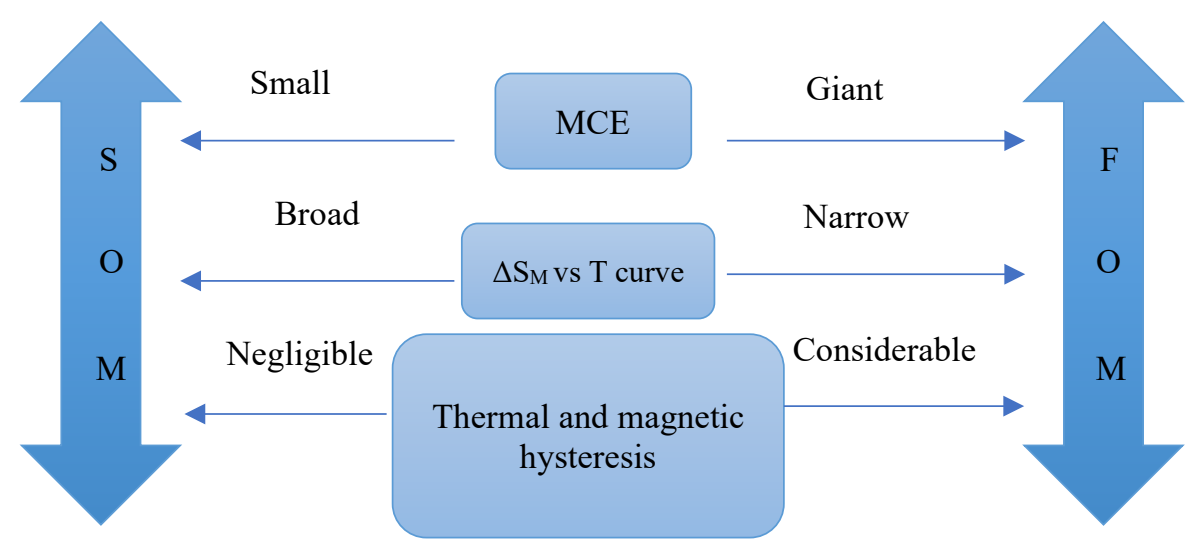

Figure 5. Differences in second and first order materials [1].

For first order transition materials, the temperature corresponding to peak $\mathrm{C}_{\mathrm{H}}$ values increases with increasing magnetic fields, whereas the peak values themselves marginally vary. With increasing $\mathrm{H}$, a SOM's peak $\mathrm{C}_{\mathrm{H}}$ value continues to reduce, and the curve broadens with insignificant change in the corresponding temperature. Boeije et al., reported that the mechanism behind the phase transition in $\mathrm{Fe}_{2} \mathrm{P}$-based materials is an isostructural transition that is equal for both first and second-order transitions [26]. They used the electron density plots to characterize the difference in behavior between first and second-order magnetic transitions. For the FOM transition the $\mathrm{T}_{\mathrm{c}}$ of the samples is much lower compared to the estimated $\mathrm{T}_{\mathrm{c}}$. The FOMs show a large thermal hysteresis. The relatively large magnetocaloric effect of a FOM material as compared to an SOM material, characterized either by the adiabatic temperature change or isothermal entropy change put FOM at advantage.

\section{Hysteresis}

The MCMs should have near-zero hysteresis to prevent energy loss. There are two types of hysteresis which occur; magnetic hysteresis (Figure 3) which occurs during an alternating magnetic field and the thermal hysteresis which occurs during cooling and heating [21]. Smith explained that a sizable and reversible temperature change near Curie temperature may actually lead to refrigeration rather than any heat dissipation during hysteresis [27]. Brey et al., introduced simulation method including hysteresis which they claimed to be more accurate than the method proposed by Nielson et al. [28, 29]. Interestingly, they reported MCM bed layered with $\mathrm{La}\left(\mathrm{Fe}_{1-\mathrm{x}} \mathrm{Si}_{\mathrm{x}}\right)_{13} \mathrm{H}_{\mathrm{y}}$ (hysteretic MCM) shows a higher COP at relatively small volumes when compared to a MCM bed layered with Gd-Er (non-hysteretic MCM). If the MCM shows large MCE then hysteresis is less significant [23].

\section{Metal Alloy Type Material}

Metal alloys are composed of metallic elements held together by metallic bonding. The metal atoms are located on a crystalline lattice with long-range translational order [17]. Researchers are studying various aspects of alloy that can be potential MCM. Jha et al. showed that addition of silver (Ag) to bulk polycrystalline manganite might produce a better MCM than a regular manganite alloy [30]. Ryan et al. studied the field and temperature induced magnetic transitions in $\mathrm{Gd}_{5} \mathrm{Sn}_{4}$ alloy but the MCE occurs at $82 \mathrm{~K}$ hence cannot be used at room temperature like many such materials [31]. As shown in Figure 2 MCM is cyclically brought under magnetic field and taken away therefore higher the magnetic field is better for MCM to respond. If higher the field is created running cost of the system is increased. Lyubina stated that any MCM which requires more than $2 \mathrm{~T}$ magnetic field has limited chance to find refrigeration application [10]. Kamilov et al. investigated the MCE in $\mathrm{La}_{1-x} \mathrm{Ag}_{\mathrm{x}} \mathrm{MnO}_{3}$ alloy and compared it with Gd [32]. By applying 2.6T of magnetic field relative RC obtained is half of $\mathrm{Gd}$ but Gd requires $5 \mathrm{~T}$ of field. Hence their material seemed interesting but it produces $\Delta \mathrm{T}_{\mathrm{ad}}$ of $2.6 \mathrm{~K}$ only. Nayak et al. studied the effect of Cobalt on Heusler alloys like, $\mathrm{Ni}_{50-\mathrm{x}} \mathrm{Co}_{\mathrm{x}} \mathrm{Mn}_{38} \mathrm{Sb}_{12}$ and proposed that Co substitution enhances MCE because Co has large magnetic moment [33].

Crystalline inter metallic compounds generally exhibit first-order transition and a larger MCE when compared to the amorphous materials [1]. The amorphous materials are generally SOMs. Table 1 represents comparison of Mn-based crystalline compounds with their curie temperatures and magnetocaloric effect in applied field change of 5T [34]. $\left(\mathrm{Fe}_{0.9} \mathrm{Mn}_{0.1}\right)_{3} \mathrm{C}$ can be assumed to be of first order based on our understanding. The narrow curve of the first-order phase transition (Figure 3) indicates that the magnetic-entropy change is associated with a small temperature range [35]. Exchanging heat during a small $\Delta \mathrm{T}_{\mathrm{ad}}$ is difficult in a practical AMR system.

Figure 6(a) represents the variation of $\mathrm{Mn}$ in Fe-Mn-C alloy and Figure 6(b) represents the variation of silicon (Si) in $\mathrm{Mn}-\mathrm{Fe}-\mathrm{P}-\mathrm{Si}-\mathrm{Ge}$ alloy with respect to both Courie temperature and entropy change. In first category increase in Mn component leads to lower $\mathrm{T}_{\mathrm{c}}$ whereas in second category increase in Si quantity leads to higher $\mathrm{T}_{\mathrm{c}}$ [17]. Thus the composition of alloy can be optimised, however most of the Mn based alloys (Table 1) require a high magnetic field of 5T. Arsenic based Mn alloy require less field but As increases thermal hysteresis [38]. Table 2 lists a different combination of materials exhibiting MCE around room temperature, with a field change of 0-5T. The table also indicate the order of magnetic transition and noteworthy is ball milling affecting magnetocaloric property of $\operatorname{Pr}_{2} \mathrm{Fe}_{17}$. Aprea et al., reported that though the rear earth metal alloy shows large MCE but they are expensive hence not at all suitable for commercialization 
of magnetic refrigeration [39]. La-Fe-Si alloy could have been potential MCM but the temperature range at which they will work is very less.

Table 1. Selected manganite alloy for room temperature refrigeration.

\begin{tabular}{|c|c|c|c|c|c|c|}
\hline Compound & $\mathrm{T}_{\mathrm{c}}(\mathrm{K})$ & $\Delta \mathrm{H}$ Tesla & $\Delta \mathrm{S}_{\mathrm{M}}(\mathrm{J} / \mathrm{kgK})$ & FOM or SOM & Remarks & [Ref] \\
\hline $\mathrm{La}_{0.7} \mathrm{Ca}_{0.2} \mathrm{Sr}_{0.1} \mathrm{MnO}_{3}: \mathrm{Ag}_{0.1}$ & 300 & 5 & 7.6 & FOM & & {$[30]$} \\
\hline$\left(\mathrm{Fe}_{0.9} \mathrm{Mn}_{0.1}\right)_{3} \mathrm{C}$ & 305 & 5 & 3.4 & - & Figure $6(\mathrm{a})$ & [34] \\
\hline$(\mathrm{MnFeP})_{0.63} \mathrm{Si}_{0.26} \mathrm{Ge}_{0.11}$ & 292 & 5 & 27 & FOM & & [34] \\
\hline$(\mathrm{MnFeP})_{0.59} \mathrm{Si}_{0.30} \mathrm{Ge}_{0.11}$ & 288 & 5 & 27 & FOM & Figure 6(b) & [34] \\
\hline $\mathrm{Ni}_{52.9} \mathrm{Mn}_{22.4} \mathrm{Ga}_{24.7}$ & 305 & 5 & 8.6 & FOM & & [35] \\
\hline $\mathrm{Mn}_{5} \mathrm{Ge}_{2.5} \mathrm{Si}_{0.5}$ & 299 & 5 & 7.8 & FOM & & {$[36]$} \\
\hline $\mathrm{MnFe}_{0.2} \mathrm{Co}_{0.8} \mathrm{Ge}$ & 289 & 5 & 9 & FOM & & {$[37]$} \\
\hline $\mathrm{Ni}_{45} \mathrm{Co}_{5} \mathrm{Mn}_{38} \mathrm{Sb}_{12}$ & 298 & 5 & 29 & FOM & & {$[33]$} \\
\hline
\end{tabular}

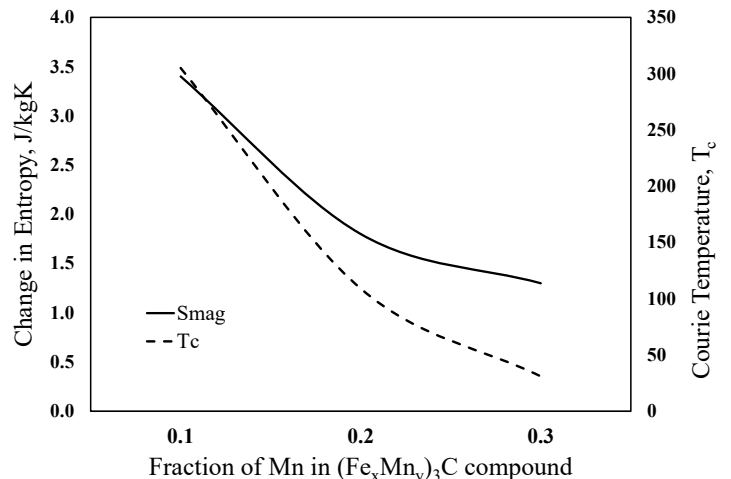

(a)

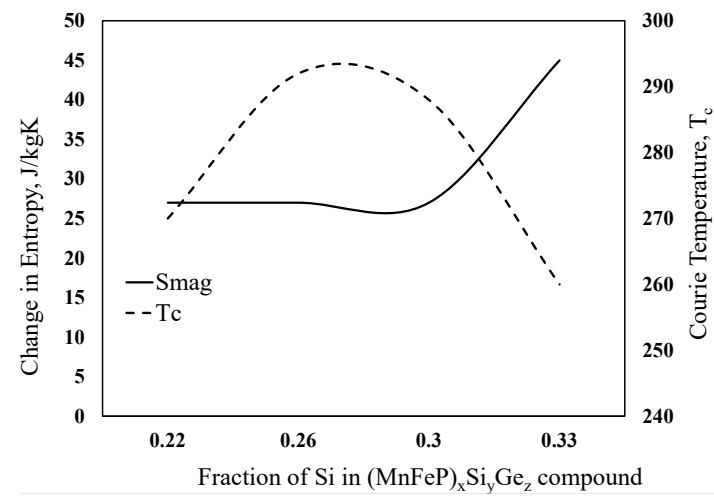

(b)

Figure 6. Influence of (a) Mn and (b) Si on MCE [31].

Table 2. List of metal and metal alloys for room temperature refrigeration.

\begin{tabular}{lcccccc}
\hline Compound & $\mathrm{T}_{\mathrm{c}} \mathrm{K}$ & $\Delta \mathrm{H}$ Tesla & $\Delta \mathrm{S}_{\mathrm{M}}(\mathrm{J} / \mathrm{kgK})$ & $\mathrm{RC}(\mathrm{J} / \mathrm{kg})$ & FOM or SOM & {$[\mathrm{Ref}]$} \\
\hline $\mathrm{Gd}$ & 294 & 1.5 & 5 & 687 & $\mathrm{SOM}$ & {$[1]$} \\
$(\mathrm{LaFe})_{11.384} \mathrm{Mn}_{0.356} \mathrm{Si}_{1.26} \mathrm{H}_{1.52}$ & 290 & 1.5 & 10.5 & 50 & $\mathrm{FOM}$ & {$[1]$} \\
$(\mathrm{LaFe})_{11.05} \mathrm{Co}_{0.94} \mathrm{Si}_{1.10}$ & 287 & 1.5 & 5.5 & 30 & $\mathrm{FOM}$ & {$[1]$} \\
$\mathrm{Pr}_{0.45} \mathrm{Sr}_{0.35} \mathrm{MnO}_{3}$ & 295 & 1.5 & 2.5 & 27 & $\mathrm{SOM}$ & {$[1]$} \\
$\mathrm{MnFeP}_{0.47} \mathrm{As}_{0.53}$ & 293 & 2 & 15 & 40 & $\mathrm{FOM}$ & {$[38]$} \\
$\mathrm{Mn}_{1.1} \mathrm{Fe}_{0.9} \mathrm{P}_{0.47} \mathrm{As}_{0.53}$ & 289 & 2 & 21 & - & $\mathrm{FOM}$ & {$[38]$} \\
$\mathrm{La}_{0.85} \mathrm{Ag}_{0.15} \mathrm{MnO}_{3}$ & 280 & 2.6 & 4.2 & 111 & FOM & {$[32]$} \\
$\mathrm{La}_{0.8} \mathrm{Ag}_{0.15} \mathrm{MnO}_{3}$ & 265 & 2.6 & 5.6 & 118 & FOM & {$[32]$} \\
$\mathrm{Pr}_{2} \mathrm{Fe}_{17}$ & 286 & 5 & 6.4 & 506 & FOM & {$[19]$} \\
$\mathrm{Pr}_{2} \mathrm{Fe}_{17}$ ball milled for $10 \mathrm{~h}$ & 296 & 5 & 4.5 & 573 & SOM & {$[19]$} \\
\hline
\end{tabular}

Other issues with metal alloy reported by several researchers include large magnetic hysteresis and high coercivity [40]. Scheibel et al., reported a detailed review focused on the identification of all relevant intrinsic and extrinsic sources of hysteresis, their microscopic origins, and way to overcome hysteresis by varying composition [41]. For example $\mathrm{LaFe}(\mathrm{Si})_{13}$ alloy exhibits a favourable small thermal hysteresis at the phase transition among various La-Fe-Si alloys. Fe$\mathrm{Rh}$ alloy possesses a very large MCE due to the cooperative contributions of all degrees of freedom in the structure but $\mathrm{Rh}$ is very expensive. In case of $\mathrm{Mn}_{3} \mathrm{GaC}$ alloy substitution of $\mathrm{C}$ by $\mathrm{N}$ shows that a tuning of the phase transition from first order to second-order character is a way to reduce the thermal hysteresis. Therefore the metallic alloys composition can be optimised.

\section{Metallic Glass Type Material}

Metallic glasses (MGs), comprise of covalent and ionic bonds, or van der Waals interactions. MGs consist of predominantly metallic elements and metallic bonds, but at the same time have an amorphous internal structure [42]. MGs can be produced by rapid solidification technique which is economical. MGs are soft magnetic materials i.e., they are easily magnetised and demagnetised with near-zero hysteresis. MGs have low coercivity and high electrical resistivity. This ensures better prevention of eddy currents. Thus MGs have broader temperature range of MCE and excellent mechanical properties [43-47] vis-a-vis machinability and durability. Guo et al. fabricated and extensively studied the MCE in Fe based amorphous materials because of tunable Curie temperature [46]. Following are the four plausible compounds, which were found suitable for room temperature refrigeration which require less magnetisation (Table 3 ). 
Table 3. List of selected metallic glass for room temperature refrigeration.

\begin{tabular}{lccccc}
\hline Material & $\mathrm{T}_{\mathrm{c}}(\mathrm{K})$ & $\Delta \mathrm{H}($ Tesla $)$ & $\Delta \mathrm{S}_{\mathrm{M}}(\mathrm{J} / \mathrm{kgK})$ & $\mathrm{RC} \mathrm{J} / \mathrm{kg}$ & {$[\mathrm{Ref}]$} \\
\hline $\mathrm{Fe}_{80-\mathrm{x}} \mathrm{Mn}_{\mathrm{x}} \mathrm{P}_{10} \mathrm{~B}_{7} \mathrm{C}_{3}$ & 235 to 350 & 2 & 0.7 to 1.24 & 88 to 147 & {$[47]$} \\
$(\mathrm{x}=13,14,15,16,18)$ & 295 & 1.5 & 1.32 & 166 & {$[48]$} \\
$\mathrm{Fe}_{88} \mathrm{Zr}_{7} \mathrm{~B}_{4} \mathrm{Cu}_{1}$ & 162 to 438 & 1.5 & 0.5 to 1 & 68 to 117 & {$[49]$} \\
$\mathrm{Fe}_{80-\mathrm{x}} \mathrm{Mn}_{\mathrm{x}} \mathrm{B}_{20}$ & 317 & 1.5 & 0.96 & 70.5 & {$[50]$} \\
$(\mathrm{x}=10,15,18,20,24)$ & $\mathrm{Co}_{71} \mathrm{Mog}_{9} \mathrm{P}_{14} \mathrm{~B}_{6}$ & & & &
\end{tabular}

Due to an inherent disorder in structure, Fe-based metallic glasses (Fe-Mn-P-B-C materials) display soft magnetic properties with nearly zero magnetic hysteresis and high electrical resistivity [51]. Wang et al. and Zhao et al., showed MGs as corrosion resistant and possess good mechanical properties (e.g. high strength and large elastic limit) [52-54]. Moreover, their Curie temperature $\left(\mathrm{T}_{\mathrm{c}}\right)$ can be manipulated and, they exhibit a broad temperature range of $\Delta \mathrm{S}_{\mathrm{M}}$ which is beneficial and likely to result a high refrigeration capacity (RC). MGs are exhibiting moderate second-order magnetic transition as par considered literature reports [55-59]. $\mathrm{Gd}_{0.55} \mathrm{Co}_{0.35} \mathrm{Mn}_{0.1}$ ribbons in the temperature range of $137-180 \mathrm{~K}$ may produce refrigeration capacity of $536.4 \mathrm{~J} / \mathrm{kg}$ [60]. Similarly $\mathrm{Gd}_{0.55} \mathrm{Al}_{0.18} \mathrm{Ni}_{0.25} \mathrm{Sn}_{0.2}$ is reported to have high $\mathrm{RC}$ value of about $827 \mathrm{~J} / \mathrm{kg}$ [61]. $\mathrm{Co}_{71} \mathrm{Mo}_{9} \mathrm{P}_{14} \mathrm{~B}_{6}$ is reported to have modest $\mathrm{RC}$ of $75 \mathrm{~J} / \mathrm{kg}$ [48]. However these materials require a magnetic field of $5 \mathrm{~T}$ and might not be suitable for commercial application.

Like metal alloys metallic glass composition can also be optimised. Zhang et al., reported the peak value of the isothermal magnetic entropy change for $\mathrm{Fe}_{(80-\mathrm{x})} \mathrm{Mn}_{\mathrm{x}} \mathrm{P}_{10} \mathrm{~B}_{7} \mathrm{C}_{3}$ metallic glass as $1.12 \mathrm{~J} / \mathrm{kgK}, \mathrm{T}_{\mathrm{c}}=295 \mathrm{~K}$ and $\mathrm{RC}=147.09 \mathrm{~J} / \mathrm{kg}$ for a field change of 0-2 $\mathrm{T}$ [47]. The variation of the isothermal magnetic entropy $\left(\Delta \mathrm{S}_{\mathrm{M}}\right)$ change with temperature is as shown in Figure 10. In case of Fe-Mn-B metallic glass varying Mn affects $T_{c}$. The peak value (for $\mathrm{x}=15$; where $\mathrm{x}$ is the varying percentage of $\mathrm{Mn}$ in the alloy) of the isothermal magnetic entropy lies beyond the room temperature change $(\sim 340 \mathrm{~K})[47]$.

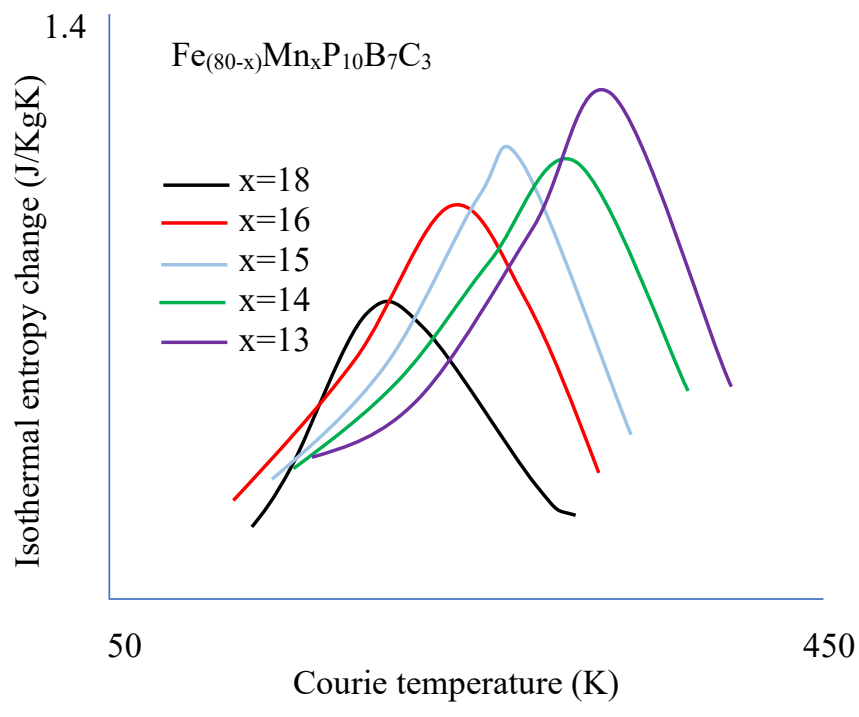

Figure 10. Temperature dependence of magnetic entropy (credit: Zhang et al., 2013) [47].

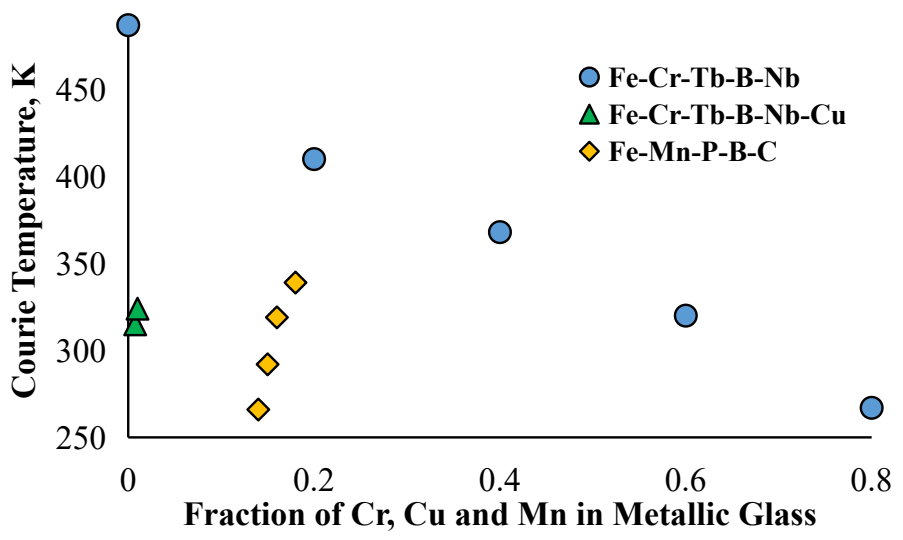

Figure 11. Variation of $\mathrm{Cr}, \mathrm{Cu}$ and $\mathrm{Mn}$ in respective MGs cause a shift in $\mathrm{T}_{\mathrm{c}}[47,62]$. 
Similar work is done by Civan et al. using $\mathrm{Fe}_{68-\mathrm{x}} \mathrm{Cr}_{\mathrm{x}} \mathrm{Tb}_{5} \mathrm{~B}_{23} \mathrm{Nb}_{4}$ where they varied chromium (Cr) as $0,2,4,6$ and 8 to reduce the concentration of $\mathrm{Fe}$ and observed shifting of $\mathrm{T}_{\mathrm{c}}$ in the similar trend as shown in Figure 10. But maximum magnetic entropy change decreased from 116 to $45.05 \mathrm{~J} / \mathrm{kg}$ [62]. To enhance the magnetic property Copper was added to form $\left.\mathrm{Fe}_{0.62} \mathrm{Cr}_{0.06} \mathrm{~Tb}_{0.05} \mathrm{~B}_{0.23} \mathrm{Nb}_{0.04}\right)_{100-\mathrm{y}} \mathrm{Cu}_{\mathrm{y}}$ where $\mathrm{y}=1$ and 0.75 (where $\mathrm{y}$ is the varying percentage of $\mathrm{Cu}$ in the alloy). Variation of $\mathrm{Cr}, \mathrm{Cu}$ and $\mathrm{Mn}$ in respective MGs cause a shift in $\mathrm{T}_{\mathrm{c}}$ (Figure 11) thus its proved that $\mathrm{T}_{\mathrm{c}}$ is a easily tunable in the MGs.

\section{ESTIMATION OF MAGNETIC MATERIAL REQUIRED}

In an AMR system cooling rate is proportional to the frequency of magnetisation. To calculate refrigeration capacity, $\mathrm{RC}$ in $\mathrm{J} / \mathrm{kg}$, we assume a suitable cycle frequency, $\mathrm{f} \mathrm{Hz}$ and then estimate maximum amount of cooling load using Eq. (3). The cycle frequency, $\mathrm{f}$ is usually less than $1 \mathrm{~Hz}$ (cycles per second); within this time the heat exchange has to take place twice as explained in if Figure 2.

$$
Q_{\max }=R C \times f
$$

Effectiveness between the MCM and auxiliary fluid, $\varepsilon=\frac{\dot{\mathrm{Q}}_{\mathrm{act}}}{\dot{\mathrm{Q}}_{\max }}$

Identify the required cooling load, $\mathrm{Q}_{\mathrm{c}}$ in $\mathrm{J} / \mathrm{s}$;

Therefore, amount of MCM required, $\mathrm{m}=\frac{\dot{\mathrm{Q}}_{\mathrm{c}}}{\dot{\mathrm{Q} a c t}}$ in $\mathrm{kg}$

Table 4 lists the amount of material required for 3 different cooling loads with $\mathrm{f}=0.625 \mathrm{~Hz}$ and, assuming effectiveness $=0.95$. This material estimation is also represented graphically in Figure 12 . RC values obtained from the literature is indicated in second column. $\mathrm{Fe}_{40} \mathrm{Ni}_{38} \mathrm{Mo}_{4} \mathrm{~B}_{18}$ is reported to produce least $\mathrm{RC}$ of $36 \mathrm{~J} / \mathrm{kg}$ whereas $\mathrm{Gd}_{60} \mathrm{Al}_{20} \mathrm{Co}_{20}$ is reported to produce $\mathrm{RC}$ of $681 \mathrm{~J} / \mathrm{kg}$. From purely cost point of view $\mathrm{Fe}_{56} \mathrm{Mn}_{24} \mathrm{~B}_{20}$ is cheap and it shows a moderate $\mathrm{RC}$ of $68 \mathrm{~J} / \mathrm{kg}$.

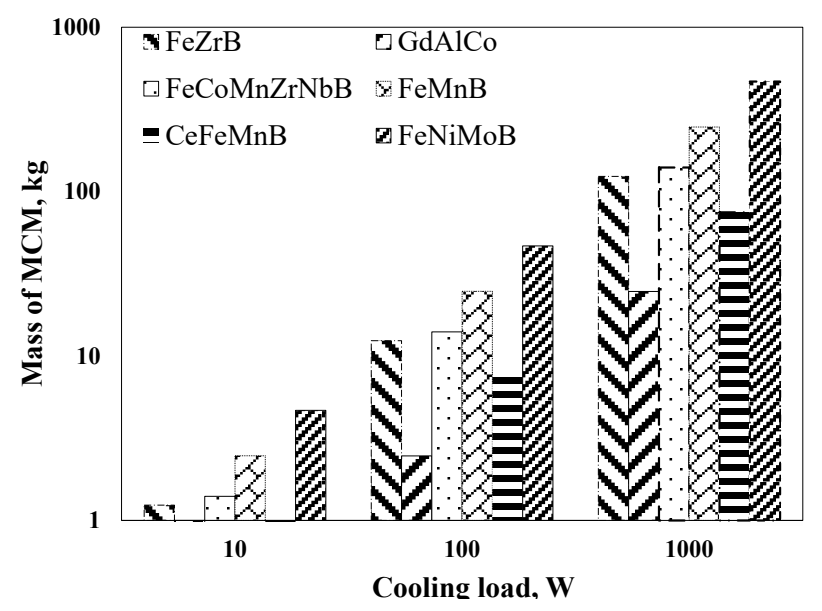

Figure 12. Variation of the mass of MCM required with cooling load.

Table 4. Estimated amount of MCM required.

\begin{tabular}{|c|c|c|c|c|c|c|}
\hline \multirow{2}{*}{ Material } & \multirow{2}{*}{$\begin{array}{c}\mathrm{S}_{\mathrm{M}} \\
(\mathrm{J} / \mathrm{kgK})\end{array}$} & \multirow{2}{*}{$\mathrm{RC}(\mathrm{J} / \mathrm{kg})$} & \multicolumn{3}{|c|}{ MCM required for $(\mathrm{kg})$} & \multirow{2}{*}{ [Ref] } \\
\hline & & & $1 \mathrm{~W}$ & $100 \mathrm{~W}$ & $10 \mathrm{~kW}$ & \\
\hline $\mathrm{Fe}_{86} \mathrm{Zr}_{9} \mathrm{~B}_{5}$ & 1.13 & 135.6 & 0.0124 & 1.24 & 124 & [46] \\
\hline $\mathrm{Gd}_{60} \mathrm{Al}_{20} \mathrm{Co}_{20}$ & 10.1 & 681 & 0.00247 & 0.247 & 24.7 & [63] \\
\hline $\mathrm{Fe}_{76} \mathrm{Co}_{6} \mathrm{Mn}_{4} \mathrm{Zr}_{8} \mathrm{Nb}_{2} \mathrm{~B}_{4}$ & 1.7 & 120 & 0.014035 & 1.4035 & 140.35 & [64] \\
\hline $\mathrm{Fe}_{56} \mathrm{Mn}_{24} \mathrm{~B}_{20}$ & 0.5 & 68 & 0.02476 & 2.476 & 247.6 & [49] \\
\hline $\mathrm{Ce}_{2} \mathrm{Fe}_{22} \mathrm{MnB}_{3}$ & $<1$ & $<112$ & 0.01496 & 1.4968 & 149.68 & [65] \\
\hline $\mathrm{Fe}_{40} \mathrm{Ni}_{38} \mathrm{Mo}_{4} \mathrm{~B}_{18}$ & 0.27 & 36 & 0.04678 & 4.678 & 467.8 & [66] \\
\hline
\end{tabular}

First Gd based refrigeration system designed in 1990 used $0.73 \mathrm{~kg}$ of Gd for a small system but it effectively did not produce much cooling [67]. AMR system theoretically proves to be more efficient (40-60\%) than conventional vapor compression system [4]. Hence material estimation is very important. Now scaled up models are reported to be working better. Jocobs et al., reported $2.5 \mathrm{~kW}$ of cooling at a range of $11 \mathrm{~K}$, using multi-layer bed containing $1.5 \mathrm{~kg}$ of $\mathrm{La}\left(\mathrm{Fe}_{1-}\right.$ ${ }_{\mathrm{x}} \mathrm{Si}_{\mathrm{x}}$ )Hy alloys [68]. Thus in the last column of Table 4 representing material required for a $10 \mathrm{~kW}$ system, vary from 24.7 $\mathrm{kg}$ to $467.8 \mathrm{~kg}$, makes the case to choose $\mathrm{Gd}_{60} \mathrm{Al}_{20} \mathrm{Co}_{20}$ as suitable MCM in given condition. 


\section{CONCLUSION}

Challenges in Magnetic refrigeration is three fold i) how system works and scope of improvement with respect to system as well as material, ii) which are the material suitable at room temperature and iii) how does system can be developed with least material requirement. Finding an easily available, stable and reversible material started with metallic alloys of various compositions all across the globe. Usage of rare earth material seems to be unavoidable due to giant magnetic moment resulting large change in magnetic entropy. But rare earth metals are costly so the lesser the amount used is better. It's not only about the room temperature refrigeration alone, the criteria is to look for a material which is durable and easy to synthesize/process along with low magnetisation. Thus the material available were limited in numbers. Various aspects are reviewed and finally, six different magnetic materials for room-temperature refrigeration are theoretically studied here. The chosen materials fall under the metallic glass category. There are challenges as well as advantages in using metallic glass over the crystalline inter metallic alloys and compounds. The amount of MCM required was estimated using a simple procedure which could ultimately enable one to estimate the size or volume and cost of the AMR system. Among the materials considered, the least amount of material will be required if $\mathrm{Gd}_{60} \mathrm{Al}_{20} \mathrm{Co}_{20}$ is used as magnetic material to build a magnetic refrigeration system.

\section{REFERENCES}

[1] Aprea C, Greco A, Maiorino A, Masselli C, Magnetic refrigeration: an eco-friendly technology for the refrigeration at room temperature. Journal of Physics: Conference Series 2015; 655: 012026.

[2] Dinesh B, Sai M, Dishal KT, Sahu D. A case study of a low power vapour adsorption refrigeration system. In: IOP Conference Series: Material Scienec Engineering 2016; 149(1): 012227.

[3] Alok P, Sahu D. Flow analysis of Isobutane (R-600a) inside an adiabatic capillary tube. In: IOP Conference Series: Material Science Engineering 2018; 310: 012148.

[4] Magnetocaloric materials. GE. Retrieved from www.geglobalresearch.com; 1 January, 2018.

[5] Barclay JA. The theory of an active magnetic regenerative refrigerator. In: 2nd Biennial Conference on Refrigeration for Cryogenic Sensors and Electron. Systems, Greenbelt, USA, pp 375-387; 1982.

[6] McMichael RD, Ritter JJ, Shull RD. Enhanced magnetocaloric effect in Gd3Ga5-xFexO12. Journal of Applied Physics 1993; 73: 6946.

[7] Zverev VI, Tishin AM. Magnetocaloric effect: From theory to practice. In: Reference module in materials science and materials engineering. Oxford: Elsevier 2016, pp. 1-11.

[8] Gruner M, Acet M, Entel P, Farle M. Mastering hysteresis in magnetocaloric materials. Philosophical Transactions of The Royal Society A Mathematical Physical and Engineering Sciences 2016; 374(2074): 20150308.

[9] Aprea C, Greco A, Maiorino A, Masselli C, Solid-state refrigeration: A comparison of the energy performances of caloric materials operating in an active caloric regenerator, Energy 2018; 165: 439-455.

[10] Lyubina J. Magnetocaloric materials for energy efficient cooling. Journal of Physics D: Applied. Physics 2017; 50: 053002.

[11] Zimm C, Jastrab A, Sternberg A, Pecharsky V et al. Description and performance of a near-room temperature magnetic refrigerator. In: Kittel P. (eds) Advances in Cryogenic Engineering. Boston: Springer, 1998, pp. 1759.

[12] Ghahremani M, Bennett LH, Torre ED, Ovichi M, Nwokoye A. Cooling factor for magnetic refrigeration systems. Cogent Physics 2014; 1(1): 979604

[13] Yu BF, Gao Q, Zhang B, Meng XZ, Chen Z. Review on research of room temperature magnetic refrigeration. International Journal of Refrigeration 2003; 26(6): 622-636

[14] Sarlah A, Kitanovski A, Poredos A, Egolf PW, Sari O, Gendre F, Besson C. Static and rotating active magnetic regenerators with porous heat exchangers for magnetic cooling. International Journal of Refrigeration 2006; 29: 1332-1339.

[15] Kulkarni Y. A Review on Magnetic Refrigeration at Room Temperature. International Journal of Innovative Research in Science Engineering and Technology 2015; 4(12): 12799-12807.

[16] Álvarez P., Llamazares JLS, Gorria P, Blanco JA. Enhanced refrigerant capacity and magnetic entropy flattening using a twoamorphous $\mathrm{FeZrB}(\mathrm{Cu})$ composite. Applied Physics Letters 2011; 99(23): 232501.

[17] Dung NH, Ou ZQ, Caron L, Zhang L, Thanh DTC, de-Wijs GA, de-Groot RA, Buschow KHJ, Brück E. Mixed Magnetism for Refrigeration and Energy Conversion. Advanced Energy Materials 2011; 1(6): 1215-1219.

[18] Magen C, Morellon L, Algarabel PA, Ibarra MR, Arnold Z, Kamarad J, Lograsso TA, Schlagel DL, Pecharsky VK, Tsokol AO, Gschneidner KA. Hydrostatic pressure control of the magneto structural phase transition in Gd5Si2Ge2 single crystals. Physics Review B 2005; 72(2): 024416.

[19] Gorria P., Llamazares JLS, Alvarez P, Perez MJ, Marcos JS, Blanco JA. Relative cooling power enhancement in magneto-caloric nanostructured Pr2Fe17. Journal of Physics D: Applied Physics 2008; 41: 192003.

[20] Belo J, Pires A, Araújo J, Pereira A. Magnetocaloric materials: From micro- to nanoscale. Journal of Materials Research 2019; 34(1): 134-157.

[21] Kitanovski A, Tušek J, Tome U, Plaznik U, Ozbolt M, Poredoš A. Magnetocaloric Energy Conversion: From Theory to Applications. Springer International Publishing; 2015.

[22] Smith A. Who discovered the magnetocaloric effect? Warburg, Weiss, and the connection between magnetism and heat, European Physics Journal H 2013; 38: 507-517. 
[23] Shen BG, Sun JR, Hu FX, Zhang HW, Cheng ZH. Recent progress in exploring magnetocaloric materials. Advanced Materials 2009; 21(45): 4545-4564.

[24] Engelbrecht K, Bahl CRH. Evaluating the effect of magnetocaloric properties on magnetic refrigeration performance, Journal of Applied Physics 2010; 108: 123918

[25] Gombi SM, Sahu D. Exploration of selected room temperature magneto caloric materials using COMSOL multiphysics, In: IOP Conference Series: Material Science Engineering 2019; 577: 012160.

[26] Boeije MFJ, Maschek M, Miao XF, Thang NV, van-Dijk NH, Brück E. Mixed magnetism in magnetocaloric materials with firstorder and second-order magnetoelastic transitions, Journal of Physics D: Applied. Physics 2017; 50: 174002.

[27] Smith A, Bahl CRH, Bjørk R, Engelbrecht K, Nielsen KK, Pryds N. Materials challenges for high performance magnetocaloric refrigeration devices, Advanced Energy Materials 2012; 2:1288-1318.

[28] Brey W, Nellis G, Klein S. Thermodynamic modeling of magnetic hysteresis in AMRR cycles. International Journal of Refrigeration 2014; 47: 85-97.

[29] Nielsen KK, Tusek J, Engelbrecht K, Schopfer S, Kitanovski A, Bahl CRH, Smith A, Pryds N, Poredos A. Review on numerical modeling of active magnetic regenerators for room temperature applications. International Journal of Refrigeration 2011; 34(3): 603-616.

[30] Jha R, Singh SK, Kumar A, Awana VPS. Room temperature magnetic entropy change and magnetoresistance in La0.70(Ca0.30xSrx)MnO3:Ag 10\% (x = 0.0-0.10). Journal of Magnetism and Magnetic Materials 2012; 324: 2849-2853.

[31] Ryan DH, Elouneg-Jamroz M, van-Lierop J, Altounian Z, Wang HB. Field and Temperature Induced Magnetic Transition in Gd5Sn4: A Giant Magnetocaloric Material, Physics Review Letters 2003; 90(11): 1172021-1172024.

[32] Kamilov IK, Gamzatov AG, Aliev AM, Batdalov AB, Aliverdiev AA, Abdulvagidov SB, Melnikov OV, Gorbenko OY, Kaul AR. Magnetocaloric effect in La1-xAgyMnO3 $(y \leq x)$ : direct and indirect measurements. Journal of Physics D: Applied Physics 2007; 40: 4413-4417.

[33] Nayak AK, Suresh KG, Nigam AK. Giant inverse magnetocaloric effect near room temperature in Co substituted NiMnSb Heusler alloys. Journal of Physics D: Applied. Physics 2009; 42 (3): 035009.

[34] Brück E, Tegus O, Thanh DTC, Trung NT, Buschow KHJ. A review on Mn based materials for magnetic refrigeration: Structure and properties, International Journal of Refrigeration 2008; 31(5): 763-770.

[35] Zhou XZ, Li W, Kunkel HP, Wlliams G, Zhang S.H. Relationship between the magnetocaloric effect and sequential magnetic phase transition in NiMnGa alloys, Journal of Applied Physics 2005; 97(3): 10M515.

[36] Zhao FQ, Dagula W, Tegus O, Buschow KHJ. Magneticentropy change in Mn5Ge3-xSix alloys. Journal of Alloys and Compounds 2006; 416: 43-45.

[37] Lin S, Tegus O, Bruck, E, Dagula W, Gortenmulder TJ, Buschow KHJ. Structural and magnetic properties of MnFe1-xCoxGe compounds. IEEE Transactions: Magnetics 2006; 42(13): 3776-3778.

[38] Bruck E, Ilyin M, Tegus O. Magnetocaloric effects in MnFe(P1-xAsx) based compounds. Journal of Magnetism and Magnetic Materials 2005; 290, 8-13.

[39] Aprea C, Greco A, Maiorino A, Masselli C. A comparison between rare earth and transition metals working as magnetic materials in an AMR refrigerator in the room temperature range, Applied Thermal Engineering 2015; 91, 767-777.

[40] Cheng YQ, Ma E. Atomic-level structure and structure-property relationship in metallic glasses. Progressive Material Science 2011; 56 (4): 379-473.

[41] Scheibel F, Gottschall T, Taubel A, Fries M, et al. Hysteresis Design of Magnetocaloric Materials—From Basic Mechanisms to Applications, Energy Technology 2018; 6: 1397 - 1428

[42] Skorvanek I, Kovac J. Magnetocaloric Behaviour in Amorphous and Nanocrystalline FeNbB Soft Magnetic Alloys. Czech Journal of Physics 2004; 54(4): 189-192.

[43] Johnson F. Shull RD. Amorphous-FeCoCrZrB ferromagnets for use as high-temperature magnetic refrigerants. Journal of Applied Physics 2006; 99(8): 08K909.

[44] Franco V, Blázquez JS, Conde CF, Conde A, A Finemet-type alloy as a low-cost candidate for high-temperature magnetic refrigeration. Applied Physics Letters 2006; 88(4): 042505.

[45] Franco V, Conde A. Magnetic refrigerants with continuous phase transitions: Amorphous and nanostructured materials. Scripta Materialia 2012; 67: 594-599..

[46] Guo DQ, Chan KC, Xia L, Yu P. Magneto-caloric effect of FexZryB100-x-y metallic ribbons for room temperature magnetic refrigeration. Journal of Magnetism and Magnetic Materials 2017; 423: 379-385.

[47] Zhang H, Li R, Xu T, Liu F, Zhang T. Near room-temperature magnetocaloric effect in FeMnPBC glasses with tunable Curie temperature. Journal of Magnetism and Magnetic Materials 2013; 347: 131-135.

[48] Caballero-Flores R, Franco V, Conde A, Knipling KE, Willard MA. Influence of Co and Ni addition on the magnetocaloric effect in Fe88-2xCoxNixZr7B4Cu1 soft magnetic amorphous alloys. Applied Physics Letters 2010; 96: 182506.

[49] Caballero-Flores R, Franco V, Conde A, Kiss LF, Influence of Mn on the magnetocaloric effect of nanoperm-type alloys. Journal of Applied Physics 2010; 108: 073921.

[50] Liu C, Li Q, Huo J, Yang W, Chang L, Chang C, Sun Y. Near room-temperature magnetocaloric effect of Co-based bulk metallic glass. Journal of Magnetism and Magnetic Materials 2018; 446: 162-165. 
[51] Luborsky FE. Butterworths Monographs in Materials. In: Luborsky FE. Amorphous metallic alloys. Butterworth Heinemann, 1983, p 1-7.

[52] Wang JF, Li R, Hua NB, Huang L, Zhang T. Ternary Fe-P-C bulk metallic glass with good soft magnetic and mechanical properties. Scripta Materialia 2011; 65: 536-539.

[53] Wang JF, Li R, Hua NB, Zhang T. Co-based ternary bulk metallic glasses with ultra-high strength and plasticity, Journal of Material Research. 2011; 26: 2072-2079.

[54] Zhao LDQ, Pan MX, Wang WH, Magnetocaloric effect in Gd-based bulk metallic glasses. Applied Physics Letters 2006; 89: 081914.

[55] Caballero-Flores R, Franco V, Conde A, Knipling KE, Willard MA. Influence of Co and Ni addition on the magnetocaloric effect in Fe88-2xCoxNixZr7B4Cu1 soft magnetic amorphous alloys. Applied Physics Letters 2010; 96: 182506.

[56] Onodera H, Yamamoto H. Magnetic properties of amorphous (Fe1-xMnx)80B20 $(0 \leq \mathrm{x} \leq 0.25)$ alloy. Journal of Physics Society Japan 1981; 50: 3575-3582.

[57] Wang YY, Bi XF. The role of $\mathrm{Zr}$ and B in room temperature magnetic entropy change of $\mathrm{Fe}-\mathrm{Zr}-\mathrm{B}$ amorphous alloys. Applied Physics Letters 2009; 95: 262501.

[58] Fang YK, Yeh CC, Hsieh CC, Chang CW, Chang HW, Chang WC, Li XM, Li W. Magnetocaloric effect in Fe-Zr-B-M (M=Mn, Cr, and Co) amorphous systems. Journal of Applied Physics 2009; 105: 07A910.

[59] Aprea C, Greco A, Maiorino A. The use of the first and of the second order phase magnetic transition alloys for an AMR refrigerator at room temperature: a numerical analysis of the energy performances. Energy Conversion and Management 2013; $70,40-55$.

[60] Mo HY, Zhong XC, Jiao DL, Liu ZW, Zhang H, Qiu WQ, Ramanujan RV. Table-like magnetocaloric effect and enhanced refrigerant capacity in crystalline Gd55Co35Mn10 alloy melt spun ribbons. Physics Letters A 2018; 382: 1679-1684.

[61] Ding D, Tang MB, Xia L. Excellent glass forming ability and refrigeration capacity of a Gd55Al18Ni25Sn2 bulk metallic glass. Journal of Alloys and Compounds 2013; 581: 828-831.

[62] Civan E, Sarlar K, Kucuk I. Improving magnetocaloric properties of $\mathrm{Fe}_{68-\mathrm{x}} \mathrm{Cr}_{\mathrm{x}} \mathrm{Tb}_{5} \mathrm{~B}_{23} \mathrm{Nb}_{4}(\mathrm{x}=0,2,4,6$ and 8$)$ metallic glasses having high glass-forming ability with tunable Curie temperature, Philosophical Magazine 2017; 97(18): 1464-1478.

[63] Shen H, Wang H, Jingshun L, Cao F, Qin F, Xing D, Chen D, Liu Y, Sun J. Enhanced magnetocaloric properties of melt-extracted GdAlCo metallic glass microwires. Journal of Magnetism and Magnetic Materials 2014; 372: 23-26.

[64] Wang GF, Li HL, Zhao ZR, Zhang XF. Stable magnetocaloric effect and refrigeration capacity in Co-doped FeCoMnZrNbB amorphous ribbons near room temperature. Journal of Alloys and Compounds 2017; 692: 793-796.

[65] Wang F, Shen J, Zhang J, Sun J, Shen B. Spin glass behavior and magnetocaloric effect in amorphous alloys Ce2Fe23-xMnxB3. Journal of Applied Physics 2009; 105: 07A944.

[66] Thanveer T, Ramanujan RV, Thomas S. Magnetocaloric effect in amorphous and partially crystallized Fe40Ni38Mo4B18 alloys, AIP Advances 2016; 6: 055322.

[67] Green G, Chafe J, Stevens J, Humphrey J, 1990, A Gadolinium-Terbium active regenerator, Advances in Cryogenic Engineering, $35,1165-1174$

[68] Jacobs S, Auringer J, Boeder A. The performance of a large-scale rotary magnetic refrigerator. International Journal of Refrigeration 2013; 37: 84-9. 